\title{
Legends of Allergy and Immunology: Sergio Bonini
}

Giuseppe Maltese ${ }^{1}$ and Guido Rasi ${ }^{2}$

${ }^{1}$ Epsom and Saint Helier University Hospitals NHS Trust

${ }^{2}$ University of Rome Tor Vergata Faculty of Medicine and Surgery

March 20, 2021

\section{Hosted file}

SB Commentary final version.pdf available at https://authorea.com/users/402827/articles/

514572-legends-of-allergy-and-immunology-sergio-bonini 